\title{
Regional differences in practice patterns and outcomes in patients treated with radical cystectomy in a universal healthcare system
}

\author{
Bassel G. Bachir, MD; ${ }^{*}$ Armen G. Aprikian, MD, FRCSC,; Yves Fradet, MD, FRCSC,; Joseph L. Chin, MD, FRCSC,; \\ Jonathan Izawa, MD, FRCSC,; Ricardo Rendon, MD, FRCSC,; Eric Estey, MD, FRCSC,; Adrian Fairey, MD, \\ FRCSC,; Ilias Cagiannos, MD, FRCSC,, Louis Lacombe, MD,FRCSC;; Jean-Baptiste Lattouf, MD, FRCSC,f

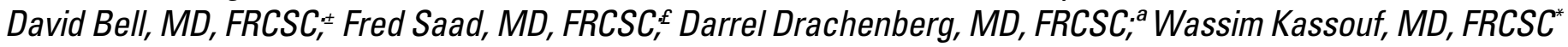

`Department of Surgery (Urology), McGill University, Montreal, QC; ${ }^{\dagger}$ Department of Surgery (Urology), Laval University, Quebec, QC; §Department of Surgery (Urology), University of Western Ontario,

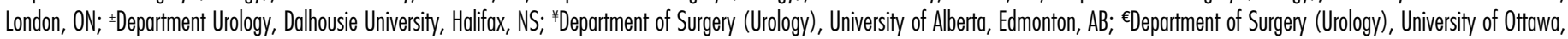
Ottawa, ON; ¿ Department of Surgery (Urology), University of Montreal, Montreal, QC; ㅁDepartment of Surgery (Urology), Winnipeg, MB

Cite as: Can Urol Assoc J 2013;7(11-12):e667-72. http://dx.doi.org/10.5489/cuaj.201 Published online November 8, 2013.

\section{Abstract}

Introduction: Our objective is to assess differences in practice patterns and outcomes across 3 regions in bladder cancer patients treated with radical cystectomy under a universal healthcare system.

Methods: In total, we included 2287 patients treated with radical cystectomy at 8 Canadian centres from 1998 to 2008. Variables included various clinico-pathologic parameters, recurrence, and death stratified into different regions.

Results: In total, 1105 patients were from the east region (group 1), 601 from the centre region (group 2), and 581 from the west region of Canada (group 3 ). The median follow-up of groups 1,2 , and 3 was $22.1,17.1$, and 28.6 months, respectively. Although the overall rate of neoadjuvant chemotherapy was low $(3.1 \%)$, rates were higher in group 2 compared with groups 1 and $3(p=0.07)$. Continent diversions and extended lymphadenectomy were performed in $23.5 \%, 8.5 \%, 23.9 \%$ and $39.7 \%, 27.7 \%, 12.6 \%$ across groups 1, 2, and 3, respectively. There were statistically significant differences in gender distribution, performance of lymphadenectomy, presence of concomitant carcinoma in situ and lymphovascular invasion across the 3 groups. There were no differences among the 3 geographical locations in terms of stage, surgical margin status, and use of adjuvant chemotherapy. The mean number of days from the transurethral resection of the bladder tumour to cystectomy was 50, 79, 69 days for groups 1, 2, 3, respectively $(p=0.0006)$. The 5 -year overall survival was $53.6 \%, 66.8 \%$, and $52.4 \%$ for groups 1,2 and 3 , respectively $(p<0.0001)$.

Conclusions: Significant variations in practice patterns were noted across different geographic regions in a universal healthcare system. Use of continent diversions, extended lymphadenectomy, and neoadjuvant chemotherapy remains low across all 3 regions. Treatment delays are significant.

\section{Introduction}

Despite the emergence of bladder preservation strategies that depend on a combination of complete transurethral resection, systemic chemotherapy and radiotherapy, radical cystectomy remains the mainstay of treatment for muscleinvasive bladder cancer, or recurrent bladder cancer refractory to intravesical therapy. With improved potency and continence rates and with the introduction of robotic and laparoscopic surgeries, radical cystectomy will likely remain the preferred treatment for bladder cancer patients who have failed local control. In this contemporary study on patients who have undergone radical cystectomy at academic centres throughout Canada, we assess regional differences in practice patterns and outcomes across 3 different regions, and possibly account for these differences as they relate to various clinical and pathological parameters.

\section{Methods}

This is a retrospective study on bladder cancer patients treated with radical cystectomy across 8 Canadian university affiliated centres across the country; centres included McGill University Health Centre and University of Montreal, Montreal, Quebec; Laval University, Quebec City, Quebec; Western University, London, Ontario; University of Alberta, Edmonton, Alberta; University of Ottawa, Ottawa, Ontario; Dalhousie University, Halifax, Nova Scotia; and University of Manitoba, Winnipeg, Manitoba. Our methodology, as well as overall outcomes of the entire cohort, has been previously published by Yafi and colleagues. ${ }^{1}$ Briefly, data were collected on all patients using a standardized template that was finalized and distributed to all centres. Members of each institution did this separately for patients operated on between 1998 and 2008, after which the data were com- 
bined using standard procedure to optimize accuracy. To account for any regional differences in practice patterns and outcomes, the data were stratified into 3 sets to account for 3 different regions: (1) East (Quebec, Nova Scotia), (2) Centre (Ontario) and (3) West (Alberta, Manitoba). Baseline demographic, clinical, pathologic, and treatment characteristics of the 3 regions were collected and included age, gender, ethnicity, smoking history, body mass index (BMI), type of diversion, concomitant carcinoma in situ (CIS) and lymphovascular invasion (LVI), as well as the presence of preoperative hydronephrosis and the time in number of days from transurethral resection of bladder tumour (TURBT) to surgery. Pathological staging and grading were performed by qualified pathologists, who adhered to the 2002 American Joint Committee on Cancer (AJCC) classification for staging and the 2004 World Health Organization (WHO) system for grading. Indications for surgery included patients with clinically documented muscle-invasive disease, or those with refractory or recurrent non-muscle invasive disease who failed repeated transurethral resections and intravesical therapy. Physician- and institution-dependent variables included the type of preoperative imaging, the performance and type of lymphadenectomy (extended or not), and the administration of adjuvant or neoadjuvant chemotherapy.

The difference between the various clinical, pathological and treatment variables across the 3 separate regions was determined using Fischer and chi-squared tests. Outcomes were determined by overall survival (OS) and disease-specific survival (DSS), and were estimated using the KaplanMeier curves. Cox regression analysis was then performed by including region to determine which of the various demographic, clinico-pathologic or treatment variables may account for any differences in survival.

\section{Results}

\section{Demographic, clinical, pathologic and treatment parameters}

The total number of patients included in this cohort was 2287, of which there were 1105 patients from eastern Canada (region 1, 49\%), 601 patients from central Canada (region 2, 26\%), and 581 patients from western Canada (region 3, 25\%). The median follow-up of groups 1, 2 and 3 was $22.1,17.1$, and 28.6 months, respectively. There were statistically significant differences in several clinicopathologic parameters, specifically gender distribution, rates of CIS, LVI, tumour grade, performance of a lymphadenectomy, type of diversion and time from TURBT to cystectomy (Table 1). This included a male-to-female distribution of $76.9 \%$ versus $23.1 \%$ for group $1,79.2 \%$ versus $20.8 \%$ for group 2 and $82.2 \%$ versus $17.6 \%$ for group $3(p=0.0293)$.

\begin{tabular}{|c|c|c|c|c|}
\hline DEMOGRAPHIC & East (Region 1) & Centre (Region 2) & West (Region 3) & $p$ value \\
\hline No. patients (\%) & $1105(49)$ & $601(26)$ & $581(25)$ & \\
\hline Mean age & 66.7 & 67.0 & 66.2 & 0.3041 \\
\hline Male (\%) & $849 / 1104(76.9)$ & $475 / 600(79.2)$ & 479/581 (82.4) & \\
\hline Female (\%) & 255/1104 (23.1) & $125 / 600(20.8)$ & 102/581 (17.6) & 0.0293 \\
\hline Mean BMI $\left(\mathrm{kg} / \mathrm{m}^{2}\right)$ & 26.3 & 28.9 & 27.4 & 0.0035 \\
\hline Smoking (\%) & $476 / 697(68.3)$ & $156 / 246(63.4)$ & $375 / 573(65.5)$ & 0.3109 \\
\hline \multicolumn{5}{|l|}{ CLINICAL } \\
\hline Hydronephrosis (\%) & $213 / 719(29.6)$ & $46 / 204(22.6)$ & $25 / 104(24.0)$ & 0.0938 \\
\hline CIS (\%) & $126 / 743(17)$ & $65 / 316(20.6)$ & $32 / 104(30.8)$ & 0.0028 \\
\hline Lymphadenectomy (\%) & $960 / 1095(87.7)$ & $464 / 498(93.2)$ & $554 / 581(95.4)$ & $<0.0001$ \\
\hline Extended lymphadenectomy (\%) & 435/1095 (39.7) & $138 / 498(27.7)$ & $73 / 581(12.6)$ & $<0.0001$ \\
\hline $\begin{array}{l}\text { Conduit (\%) } \\
\text { Continent (\%) }\end{array}$ & $\begin{array}{l}833 / 1089(76.5) \\
256 / 1089(23.5)\end{array}$ & $\begin{array}{c}421 / 460(91.5) \\
39 / 460(8.5)\end{array}$ & $\begin{array}{l}439 / 577(76.1) \\
138 / 577(23.9)\end{array}$ & $<0.0001$ \\
\hline Neoadjuvant chemotherapy (\%) & $26 / 1096(2.4)$ & $23 / 515(4.5)$ & $18 / 591(3.1)$ & 0.0747 \\
\hline Mean time to cystectomy (days) & 50 & 79 & 69 & 0.0006 \\
\hline Median follow-up (months) & 22.1 & 17.1 & 28.6 & \\
\hline \multicolumn{5}{|l|}{ PATHOLOGIC } \\
\hline LVI (\%) & $230 / 517$ (44.5) & 79/176 (44.9) & $172 / 574(30)$ & $<0.0001$ \\
\hline High-grade (\%) & $625 / 969(64.5)$ & $271 / 324(83.6)$ & $517 / 568(91)$ & $<0.0001$ \\
\hline Positive surgical margin (\%) & 73/1019 (7.2) & $39 / 423(9.2)$ & $61 / 574(10.6)$ & 0.0525 \\
\hline Pathologic $T$ stage $(\geq T 2)(\%)$ & 799/1076 (74.3) & $371 / 525(70.7)$ & $413 / 562(73.5)$ & 0.3085 \\
\hline Pathologic $\mathrm{N}$ stage $(\mathrm{N}+)(\%)$ & $271 / 1001(27.1)$ & $135 / 559(24.2)$ & $138 / 543(25.4)$ & 0.4325 \\
\hline Adjuvant chemotherapy (\%) & 204/1095 (18.6) & $88 / 387(22.7)$ & 109/581 (18.8) & 0.1902 \\
\hline
\end{tabular}


Overall, $87.7 \%$ of patients from group 1 underwent a lymphadenectomy, $93.2 \%$ from group 2 and $95.4 \%$ from group $3(p<0.0001)$. The use of continent diversions was low across Canada with rates of ileal conduit formation versus continent diversions for the 3 groups being $76.5 \%$ versus $23.5 \%, 91.5 \%$ versus $8.5 \%$ and $76.1 \%$ versus $23.9 \%$ for groups 1,2 and 3 respectively $(p<0.0001)$. The mean time from TURBT to cystectomy was 50,79, 69 days for groups 1 , 2 and 3 , respectively $(p=0.0006)$. There was no statistically significant difference among patients from the groups with respect to mean age, smoking status, rate of surgical margin positivity, and pathologic stage. Although rates of perioperative chemotherapy were very low across Canada, there was a trend towards higher rates of perioperative chemotherapy in region 2 . When sub-selecting for patients with pathologic non-organ confined disease (pT3-4 or pTxN+), there was no statistically significant difference in the rate of adjuvant chemotherapy $(31.9 \%$ vs. $35.8 \%$ vs. $30.7 \%$ in regions 1,2 and $3, p=0.4250)$. However, there was a trend towards higher rates of neoadjuvant chemotherapy in region 2 compared to regions 1 and $3(4.5 \%$ vs. $2.4 \% 3.1 \%, p=0.07)$.

\section{OS and DSS across the 3 regions}

On Kaplan-Meier survival analysis, there was a statistically significant difference in 5 -year OS $(53.6 \%$ vs. $66.8 \%$ vs. $52.4 \%$ for groups 1,2 and 3 ) and DSS (64.6\% vs. $75 \%$ vs. $60.4 \%)$ among the 3 regions $(p<0.0001)$ (Fig. 1 ). Multivariate Cox regression analysis revealed that higher pathologic stage, positive surgical margin status, and number of positive nodes were associated with decreased OS and DSS. The use of adjuvant chemotherapy, total number of nodes resected, as well as central region, were independent prognostic factors for prolonged OS and DSS on multivariate analysis (Table 2).

\section{Discussion}

This study reveals important variations in practice patterns in bladder cancer patients treated with radical cystectomy across Canada. There was an underutilization of perioperative chemotherapy and continent diversions across the regions. Treatment delays remain significant regardless of geographic location.

Several studies have reported the benefits of perioperative chemotherapy (particularly neoadjuvant chemotherapy) in patients with muscle invasive bladder cancer. ${ }^{2-7}$ In our analysis, the overall rate of neoadjuvant chemotherapy was low and ranged from $2.4 \%$ in region 1 to $4.5 \%$ and $3.1 \%$ in regions 2 and 3, respectively. Despite the fact that the evidence for use of adjuvant chemotherapy is much less robust compared with the neoadjuvant setting, the overall use of adjuvant chemotherapy was higher across all 3 regions and ranged from $31 \%$ to $36 \%$ in patients with nonorgan confined disease. Although no statistically significant difference existed among the 3 regions in the overall use of adjuvant or neoadjuvant chemotherapy, there is a trend towards higher rates of neoadjuvant chemotherapy in region 2 . This can partly explain the improved survival rates from region 2. Data from the national cancer database in the United States reveal that while the proportion of patients who underwent radical cystectomy has remained stable, there has been an increase in the number of patients who received chemotherapy over the last few years. ${ }^{8}$ These trends were also paralleled in our patient population and revealed the evolving treatment paradigm for patients with bladder cancer despite the progressive, yet timid, adoption of perioperative chemotherapy across all regions. ${ }^{1}$ This is highlighted by the fact that after 2005 , only $7 \%$ of patients undergoing radical cystectomy received neoadjuvant chemotherapy.

Analysis of the 3 regions also revealed a statistically significant difference in the type of urinary diversion performed, with the rates of continent bladder substitutes ranging from

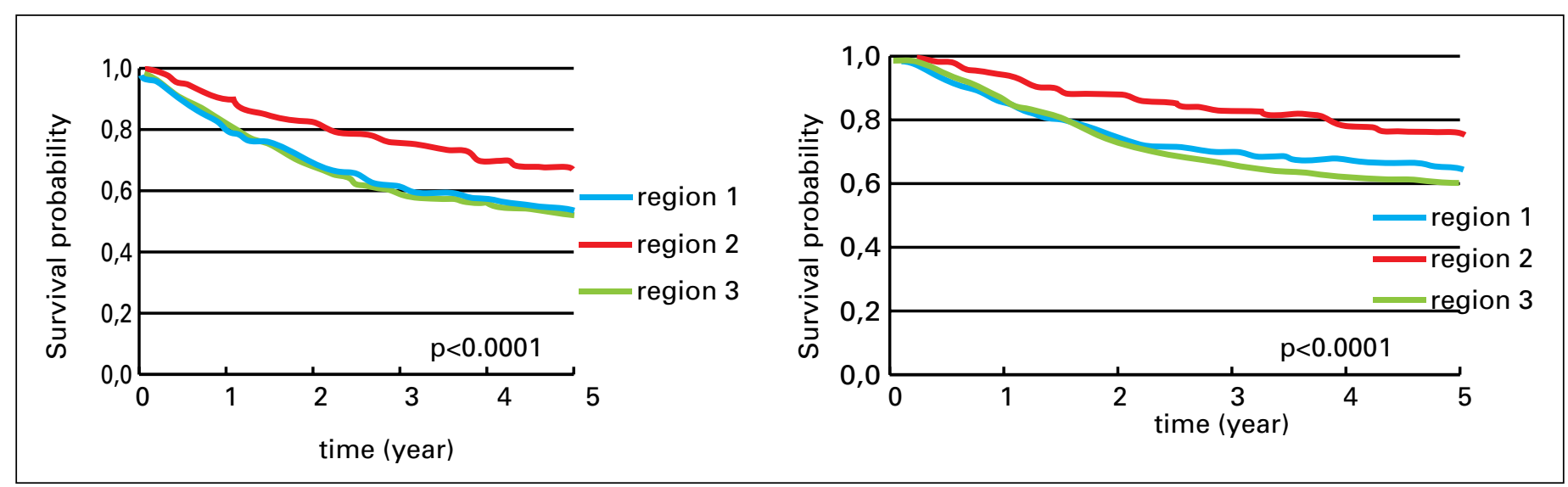

Fig. 1. Kaplan-Meier survival curves of overall (A) and disease-specific (B) survival stratified by geographic regions across Canada. 


\begin{tabular}{|c|c|c|c|c|c|c|}
\hline & \multicolumn{3}{|c|}{ Multivariate analysis OS } & \multicolumn{3}{|c|}{ Multivariate analysis DSS } \\
\hline & HR & $95 \% \mathrm{Cl}$ & $p$ value & HR & $95 \% \mathrm{Cl}$ & $p$ value \\
\hline \multicolumn{7}{|l|}{ Gender } \\
\hline Male & 1.0 & & & 1.0 & & \\
\hline Female & 1.097 & $0.890-1.353$ & 0.3856 & 1.130 & $0.889-1.435$ & 0.3184 \\
\hline Age & 1.008 & $0.999-1.018$ & 0.0699 & 1.001 & $0.991-1.011$ & 0.8377 \\
\hline Diversion & 0.878 & $0.692-1.114$ & 0.2832 & 0.859 & $0.655-1.127$ & 0.2731 \\
\hline \multicolumn{7}{|l|}{ Region } \\
\hline East & 1.0 & & & 1.0 & & \\
\hline Centre & 0.604 & $0.397-0.920$ & 0.0189 & 0.592 & $0.353-0.995$ & 0.0476 \\
\hline West & 0.968 & $0.789-1.187$ & 0.7526 & 1.093 & $0.864-1.384$ & 0.4582 \\
\hline Pathological stage $>\mathrm{T} 2$ & 2.753 & $2.065-3.670$ & $<0.0001$ & 3.318 & $2.317-4.752$ & $<0.0001$ \\
\hline Positive margins & 1.730 & $1.334-2.242$ & $<0.0001$ & 1.913 & $1.433-2.554$ & $<0.0001$ \\
\hline Nodal status $(\mathrm{N}+)$ & 2.455 & $1.955-3.083$ & $<0.0001$ & 2.487 & $1.915-3.230$ & $<0.0001$ \\
\hline No. positive nodes & 1.044 & $1.002-1.088$ & 0.0398 & 1.060 & $1.015-1.107$ & 0.0082 \\
\hline No. resected nodes & 0.985 & $0.971-0.999$ & 0.0365 & 0.978 & $0.961-0.994$ & 0.0085 \\
\hline Adjuvant chemotherapy & 0.599 & $0.476-0.753$ & $<0.0001$ & 0.630 & $0.488-0.815$ & 0.0004 \\
\hline
\end{tabular}

HR: hazard ratio; Cl: confidence interval; OS: overall survival; DSS: disease-specific survival.

$8.5 \%$ to $23.9 \%$ across Canada. This still represents a low percentage of patients receiving continent diversions in tertiary academic centres across all regions, with the rate of orthotopic reservoirs reported as high as $30 \%$ to $64 \%$ in higher volume tertiary centres..$^{9,10}$

Several reports have also supported the beneficial role of lymphadenectomy and an extended lymphadenectomy during radical cystectomy, ${ }^{11-16}$ with the trend towards removing more rather than less nodes. ${ }^{17-19}$ More recently, several lymph node dissection variables, including total number of nodes resected, number of positive nodes, as well as the ratio of number of positives/total number of nodes resected (lymph node density), have been of prognostic relevance in patients with bladder cancer. ${ }^{20-22}$ Overall, performance of a lymphadenectomy was only $91 \%$, in this study ranging from $87.7 \%$ in region 1 to $95.4 \%$ in region 3 . Interestingly, $5 \%$ of patients reported to have undergone a lymphadenectomy had zero nodes identified on final pathology. Differences in practice patterns between urologists in Canada and the United States have been noted; Canadian urologists are generally less aggressive in screening, recommending radical definitive surgery and conducting stringent follow-up. ${ }^{23,24}$ However, a recent survey revealed that the use of lymphadenectomy in the United States is as low as $70 \%$, with nearly 1 in 3 patients not undergoing a lymphadenectomy during radical cystectomy. ${ }^{25}$

With regards to extent of Iymphadenectomy, only $29.7 \%$ of our entire cohort was reported to have received an extended lymphadenectomy by the treating physician $(39.7 \%, 27.7 \%, 12.6 \%$ for patients in regions 1,2 and 3 , respectively), similar to rates of $22 \%$ observed in the United States. ${ }^{1,25}$ Interestingly, the average number of nodes removed in patients who had undergone an extended versus limited lymphadenectomy was low (13.4 vs. 7.8 nodes, $p<0.0001)$. This further highlights the need for not only improved utilization of lymphadenectomy in patients with invasive bladder cancer, but more importantly ensured measures that can better reflect the quality and extent of the dissection across all regions in Canada.

Despite clear national and international guidelines on minimizing surgical wait times and a published Canadian consensus report recommending a maximum wait time of between 2 to 4 weeks ( 14 to 28 days) for all cancer surgeries, including radical cystectomy, ${ }^{26}$ our study reveals significant delays from last TURBT to cystectomy across all regions (median 50 to 79 days). Reasons for these delays are many and potentially include limited access to resources, such as operating room time and imaging studies, as well as prolonged referral delays from community physicians. Although patients will definitely wait longer if neoadjuvant chemotherapy is administered, we do not suspect this factor to have contributed significantly since only $3.1 \%$ of all patients received neoadjuvant chemotherapy. ${ }^{1}$

Although one would expect similar survival outcomes for patients in a universal healthcare system despite different geographic regions, this was not shown in this study. However, our mismatched patient cohorts with variable follow-up intervals and neoadjuvant chemotherapy rates may have contributed to this apparent difference in survival. In addition, it must be acknowledged that although most academic centres were included, we did not capture data from every centre that performs radical cystectomy in Canada; as such, it is possible that our results may not accurately and comprehensively reflect regional differences in practice patterns.

In this study, significant differences were noted in practice patterns across the 3 regions. Development of new molecular markers that help identify biologically aggressive 
disease and predictors of response to neoadjuvant chemotherapy may eventually be used to help guide physicians and patients in standardizing treatment decisions. ${ }^{27-29}$ Although we believe that standardized national recommendations are instrumental and can help guide physicians and patients in deciding on treatment regimens, the more important question is how to encourage physicians to adhere to these established guidelines.

\section{Conclusion}

Important variations in practice patterns were noted among patients treated across 3 distinct geographic regions in a universal healthcare system. Most notably, the use of continent bladder substitutes remains low across Canada, with underutilization of perioperative chemotherapy and extended lymphadenectomy across the regions. Significant time delays to cystectomy remain across the regions.

Acknowledgements: Dr Wassim Kassouf is a recipient of a Research Scholar Award from the Fonds de recherche du Québec - Santé (FRSQ).

Competing interests: Dr. Aprikian is a board observer for Bioniche Inc., a member of the Speakers bureau for Amgen, Abbvie and Astellas. He has also received grants from Amgen, Astellas and Abbvie. Moreover, he has participated in a clinical trial within the past 2 years for Astellas. Dr. Fradet is the Chief Medical Officer on the Advisory Boards for DiagnoCure, AstraZeneca, Janssen, Astellas, and Amgen. He has also received hororaria and salary from DiagnoCure, AstraZeneca, Janssen, Astellas, Amgen, and GammaDynacare. He holds investments in Abbott and is participating in several trials in GU cancers. Dr. Rendon is a member of the Advisory Board and the Speakers bureau for Amgen, Astellas, Ferring and Janssen. Dr. Lacombe has no competing financial or personal interests. Dr. Saad is an Advisory Board member for Amgen, Astellas, Janssen, Abbott, Sanofi and Bayer. He has also received research grants and honoraria from Amgen, Astellas, Janssen, Abbott, Sanofi and Bayer. Dr. Saad has also participated in clinical trials in the past 2 years for Amgen, Astellas, Janssen, Sanofi and Bayer. Dr. Drachenberg has attended Advisory Boards for Astellas and Janssen and has been a speaker for Amgen and Actavis (formerly Watson). He has also been an investigator in clinical trials run by Cancer Care Manitoba (CCMB). Dr. Kassouf is an Advisory Board member and a speaker for Amgen and Astellas. He has also received grants and honoraria from these companies. He is currently participating in unpaid clinical trials within the past 2 years. Dr. Izawa is a member of the Advisory Board for Janssen and Actavis (formerly Watson). He has also received honoraria from Abbott. Dr. Bell is a member of the Advisory Board for, and has received honoraria from Abbott, Pfizer and Paladin. He also holds investments in Abbott and Pfizer. Dr. Chin, Dr. Estey and Dr. Fairey all declare no competing financial or personal interests.

This paper has been peer-reviewed.

\section{References}

1. Yafi FA, Aprikian AG, Chin JL, et al. Contemporary outcomes of 2287 patients with bladder cancer who were treated with radical cystectomy: a Canadian multicentre experience. BJU Int 2011;108:539-45. http://dx.doi.org/10.1111/i.1464-410X.2010.09912.x
2. Stenzl A, Cowan NC, De Santis M, et al. Treatment of muscle-invasive and metastatic bladder cancer: update of the EAU guidelines. Eur Urol 2011;59:1009-18. http://dx.doi.org/10.1016/j.eururo.2011.03.023

3. Sherif $A$, Rintala $E$, Mestad 0 , et al. Neoadjuvant cisplatin-methotrexate chemotherapy for invasive bladder cancer - nordic cytectomy trial 2. Scand J Urol Nephrol 2002;36:419-25. http://dx.doi. org/10.1080/003655902762467567

4. Hall R. Updated results of neoadjuvant cisplatin (C), methotrexate (M), and vinblastine (V) chemotherapy for muscle-invasive bladder cancer. Proc Annual Meeting of the American society of clinical oncology 2001;21:78.

5. Advanced Bladder Cancer (ABC) Meta-analysis Collaboration. Adjuvant chemotherapy in invasive bladder cancer: a systematic review and meta-analysis of individual patient data advanced bladder cancer (ABC) meta-analsysis collabortaion. Eur Urol 2005;48:189-99. http://dx.doi.org/10.1016/i. eururo.2005.04.005

6. Grossman HB, Natale RB, Tangen CM, et al. Neoadjuvant chemotherapy plus cystectomy vcompared with cystectomy alone for locally advanced bladder cancer. N Engl J Med 2003;349:859-66. http://dx.doi. org/10.1056/NEJMoa022148

7. Advanced Bladder Cancer (ABC) Meta-analysis Collaboration. Neoadjuvant chemotherapy in invasive bladder cancer: update of a systematic review and meta-analysis of individual patient data advanced bladder cancer (ABC) meta-analysis collaboration. Eur Urol 2005;48:202-5. http://dx.doi.org/10.1016/i. eururo.2005.04.006

8. Fedeli U, Fedewa $S A$, Ward EM. Treatment of muscle invasive bladder cancer: evidence from the National Cancer Database, 2003 to 2007. J Urol 2011;185:72-8. http://dx.doi.org/10.1016/i. juro.2010.09.015

9. Bader $P$, Westermann $D$, Frohneberg $D$. Urinary diversions: which one one is right for which patient? [in German]. Der Urologe Ausg A 2009;48:127-36. http://dx.doi.org/10.1007/s00120-008-1924-x

10. Lowrance WT, Rumohr JA, Clark PE, et al. Urinary diversion trends at a high volume, single American tertiary care center. J Urol 2009;182:2369-74. http://dx.doi.org/10.1016/i.juro.2009.07.026

11. Brunocilla $\mathrm{E}$, Pernetti $R$, Martorana $\mathrm{G}$. The role of pelvic lymph node dissection during radical cystectomy for bladder cancer. Anticancer Res 2011;31:271-5.

12. Jensen JB, Ulhoi BP, Jensen KM. Extended versus limited lymph node dissection in radical cystectomy: Impact on recurrence pattern and survival. Int J Urol 2012;19:39-47. http://dx.doi.org/10.1111/ j.1442-2042.2011.02887.x. Epub 2011 Nov 3.

13. Lerner SP. The role and extent of pelvic lymphadenectomy in the management of patients with invasive urothelial carcinoma. Curr Treat Options Oncol 2009;10:267-74. http://dx.doi.org/10.1007/ s1 1864-009-0107-3

14. Bruins HM, Stein JP. Risk factors and clinical outcomes of patients with node-positive muscleinvasive bladder cancer. Expert Rev Anticancer Ther 2008;8:1091-101. http://dx.doi. org/10.1586/14737140.8.7.1091

15. Stein JP. Lymphadenectomy in bladder cancer: how high is "high enough"? Urol Oncol 2006;24:349-55. http://dx.doi.org/10.1016/i.urolonc.2005.07.013

16. Mogorovich A, Giannarini G, Manassero F, et al. The role and extension of lymphadenectomy in bladder cancer: a review of the current literature. Arch Ital Urol Androl 2009;81:233-41.

17. Karadeniz T, Baran C, Topsakal M. et al. Importance of the number of retreived lymph nodes during cystectomy. Urol J 2011;8:197-202.

18. Zehnder P, Studer UE, Skinner EC, et al. Super extended versus extended pelvic lymph node dissection in patients undergoing radical cystectomy for bladder cancer: a comparative study. J Urol 201 1;186:1261-8. http://dx.doi.org/10.1016/i.juro.2011.06.004

19. Elzayat EA, Al-Zahrani AA. Pelvic lymphadenectomy in the treatment of invasive bladder cancer: literature review. Adv Urol 2011;701481.

20. May M, Herrmann E, Bolenz C, et al., Lymph node density affects cancer-specific survival in patients with lymph node-positive urothelial bladder cancer following radical cystectomy. Eur Urol 2011;59:712-8. http://dx.doi.org/10.1016/j.eururo.2011.01.030

21. Jensen JB, Ulhoi BP, Jensen KM. Evaluation of different lymph node (LN) variables as prognostic markers in patients undergoing radical cystectomy and extended $L N$ dissection to the level of the inferior mesenteric artery. BJU Int 2012 Feb;109(3):388-93. http://dx.doi.org/10.1111/i.1464-410X.2011.10369.x. Epub 2011 Aug 18

22. Kassouf $\mathrm{W}$, Svatek $\mathrm{RS}$, Shariat $\mathrm{SF}$, et al. Critical analysis and validation of lymph node density as prognostic variable in urothelial carcinoma of bladder. Urol Oncol 2013;31:480-6. http://dx.doi.org/10.1016/i. urolonc.2011.02.011. Epub 2011 Apr 8. 2011.

23. Chung D, Hersey K, Fleshner N. Differences between urologists in United States and Canada in approach to bladder cancer. Urology 2005;65:919-25. http://dx.doi.org/10.1016/i.urology.2004.11.028

24. Dalbagni $\mathrm{G}$, Bochner $B \mathrm{~B}$, Cronin $\mathrm{A}$, et al. A plea for a uniform surveillance schedule after radical cystectomy. J Urol 2011;185:2091-6. http://dx.doi.org/10.1016/i.juro.2011.01.082

25. Hedgepeth RC, Zhang Y, Skolarus TA, et al. Variation in use of lymph node dissection during radical cystectomy for bladder cancer. Urology 2011;77:385-90. http://dx.doi.org/10.1016/j.urology.2010.08.050 
Bachir et al.

26. Fradet $Y$, Aprikian $A$, Dranitsaris $G$, et al. Does prolonging the time to bladder cancer surgery affect long-term cancer control: a systematic review of the literature. Can J Urol 2006;13 (Suppl 3):37-47.

27. Jensen JB, Munksgaard PP, Sorensen CM, et al. High expression of karyopherin-alpha2 defines poor prognosis in non-muscle-invasive bladder cancer and in patients with invasive bladder cancer undergoing radical cystectomy. Eur Urol 2011;59:841-8. http://dx.doi.org/10.1016/i.eururo.2011.01.048

28. Chen W, Luo JH, Hua WF, et al. Overexpression of EIF-5A2 is an independent predictor of outcome in patients of urothelial carcinoma of the bladder treated with radical cystectomy. Cancer Epidemiol Biomarkers Prev 2009;18:400-8. http://dx.doi.org/10.1158/1055-9965.EPI-08-0754
29. Shariat SF, Karakiewicz PI, Godoy G, et al. Survivin as a prognostic marker for urothelial carcinoma of the bladder: a multicenter external validation study. Clin Cancer Res 2009;15:7012-9.

Correspondence: Dr. Wassim Kassouf, Division of Urology, McGill University Health Centre, 1650 Cedar Avenue, Rm L8-315, Montreal, QC H3G 1A4; fax: 514-934-8297; wassim.kassouf@muhc.mcgill.ca 